\title{
AS FACULDADES DA MIMESE, IMAGINAÇÃO E MEMÓRIA NA INFÂNCIA: 0 ENTRELAÇAR DO AMOR E DO PENSAMENTO
}

\author{
MARA SALGADO ${ }^{1}$ \\ ORCID: https://orcid.org/0000-0001-5795-2561 \\ ALEXANDRE FERNANDEZ VAZ ${ }^{2}$ \\ ORCID: https://orcid.org/0000-0003-4194-3876
}

\begin{abstract}
RESUMO: O objetivo deste artigo é apresentar os resultados da pesquisa acerca do entrelaçamento do amor e do pensamento na infância em Theodor W. Adorno, cujas faculdades da mimese, imaginação e memória marcam a infância como uma experiência de outra ordem da razão, mais mimética, imaginativa, que alimenta a memória da natureza no humano, contudo, sem isentar-se das forças históricas coercivas que constituem as condições objetivas da vida. Privilegiou-se como método da investigação teórica a análise dos conceitos de mimese, imaginação e memória em suas relações com a infância e com a base pulsional que possibilita o movimento do amor, fundamentando-se em Adorno e seus interlocutores da Teoria Crítica da Sociedade, em especial Walter Benjamin, e na Psicanálise freudiana. Tais faculdades operam no pensamento por meio de mecanismos psíquicos de defesa da consciência que entrelaçam os processos mais primitivos da natureza humana ao desenvolvimento dos processos superiores que a cultura possibilita.
\end{abstract}

Palavras-chave: Infância, faculdades do pensamento, amor, Theodor W. Adorno, Teoria Crítica da Sociedade.

\section{THE FACULTIES OF MIMESE, IMAGINATION AND MEMORY IN CHILDHOOD: THE INTERTWINING OF LOVE AND THOUGHT}

\begin{abstract}
The purpose of this article is to present the results of the research on the intertwining of love and thought in childhood in Theodor W. Adorno, whose faculties of mimesis, imagination and memory mark childhood as an experience of a different order of reason, more mimetic, imaginative, which feeds the memory of nature in the human, yet without being exempt from the coercive historical forces that constitute the objective conditions of life. The analysis of the concepts of mimesis, imagination and memory in their relations with childhood and with the instinctual basis that allows the movement of love, based on Adorno and his interlocutors of the Critical Theory of Society, especially Walter Benjamin, and in Freudian Psychoanalysis. These faculties operate in thought through psychic mechanisms of defense of consciousness that intertwine the most primitive processes of human nature to the development of the higher processes that culture enables.
\end{abstract}

Keywords: Childhood, faculties of thought, love. Theodor W. Adorno. Critical Theory of Society.

\footnotetext{
${ }^{1}$ Professora no Departamento de Psicologia da Universidade do Estado de Minas Gerais - UEMG. Divinópolis, MG, Brasil. <marasalgado.ms@gmail.com>

2 Professor na Universidade Federal de Santa Catarina, Centro de Ciências da Educação, Departamento de Estudos Especializados em Educação e nos Progrmas de Pós-Graduação em Educação - PPGE e Pós-Graduação Interdisciplinar em Ciências Humanas - PPGICH. Florianópolis, SC, Brasil. <alexfvaz@uol.com.br> 


\section{LAS FACULTADES DE MIMESIS, IMAGINACIÓN Y MEMORIA EN LA INFANCIA: EL ENTRELAZAR DEL AMOR Y EL PENSAMIENTO}

RESÚMEN: El propósito de este artículo es presentar los resultados de la investigación sobre el entrelazamiento del amor y el pensamiento en la infancia en Theodor W. Adorno, cuyas facultades de mimesis, imaginación y memoria marcan a la infancia como una experiencia de otro orden de la razón, más mimético, imaginativo, que alimenta la memoria de la naturaleza en el ser humano, sin embargo, sin eximirse de las fuerzas históricas coercitivas que constituyen las condiciones objetivas de la vida. El análisis de los conceptos de mimesis, imaginación y memoria en sus relaciones con la infancia y con la base pulsional que permite el movimiento del amor fue privilegiado como método de investigación teórica, basado en Adorno y sus interlocutores de la teoría crítica de la sociedad, especialmente Walter Benjamin, y en Psicoanálisis freudiana. Tales facultades operan en el pensamiento a través de mecanismos psíquicos de defensa de la conciencia que entrelazan los procesos más primitivos de la naturaleza humana con el desarrollo de los procesos superiores que la cultura hace posible.

Palabras clave: Infancia, facultades del pensamento, amor. Theodor W. Adorno. Teoría Crítica de la Sociedad. 


\section{INTRODUÇÃO}

Este artigo traz os resultados de pesquisa ${ }^{3}$ acerca do entrelaçamento do amor e do pensamento na infância, com foco na participação das faculdades da mimese, da imaginação e da memória nesse entrelaçar. A partir das contribuições de Theodor W. Adorno é possível compreender que o pensamento capaz de conservar algo de um momento original da mimese, da imaginação e da memória, faculdades que compõem de modo mais proeminente a forma de operar do pensamento na infância, pode encontrar brechas nas condições enrijecidas da racionalidade para a realização de seu potencial intelectual-sensível, ou seja, entrelaçar-se ao amor e superar a frieza que limita tal potencial.

A infância está presente em algumas passagens da obra de Theodor W. Adorno, por um lado como lugar das primeiras utopias, a pátria ansiada e, desde sempre, inabitada, que se torna falsa a qualquer tentativa de resgate, mas ilumina o desejo outrora experimentado num jogo com o corpo e o pensamento, o sonho e a realidade, a experiência de outra ordem da razão - mais mimética e imaginativa, que alimenta a memória da natureza no humano -, sem, contudo, estar isenta das forças históricas dominantes que incidem sobre os processos de subjetivação. Por outro lado, e tirando proveito dessa razão que não abandonou sua intimidade com a natureza, a infância é reconhecida por Adorno como o espaço e o tempo propícios para as tentativas de combater a barbárie desde seus primeiros indícios. Trata-se, portanto, da compreensão da racionalidade adulta "esclarecida", a qual está submetida à educação das crianças, por meio do emaranhado das condições objetivas para a vida humana, que ora permite a aparição do melhor da infância, ora revela a infantilidade ferida que perverte os impulsos agressivos e as ilusões sobre a realidade em projeção violenta entre os indivíduos (SALGADO, 2017; SANTOS, 2018).

O lar, a pátria da infância, já é para Adorno a expressão dialética do pensamento esclarecido que resguarda momentos de resistência ao amparar na subjetividade, não totalmente reificada, momentos racionais e irracionais (VAZ, 2006). Ou seja, o pensamento na infância, ao alcançar certa fruição mimética e imaginativa, apresenta também as contradições que marcam a razão esclarecida, entretanto, sem falseá-las, nem tanto por autenticidade, mas porque o corpo - ainda não de todo domesticado - brinca, mimetiza e, assim, transforma por meio do jogo o conteúdo ideológico social que com o passar dos anos aprendemos a justificar, com frequência, ao obedecê-lo.

Nas contribuições de Adorno acerca da infância é possível perceber a influência da Psicanálise de Freud, mas também a interlocução com Walter Benjamin, Max Horkheimer e Herbert Marcuse; autores cujos pensamentos apresentam aproximações e distanciamentos teóricometodológicos, mas, no que tange à infância, remetem a movimentos da formação do indivíduo a partir da relação entre natureza e cultura. Num primeiro movimento, a infância traz a promessa para uma "vida certa", como escreveu Santos (2018, p. 324), deixando pistas para um caminho de rememoração sensível que possibilita na vida adulta a autorreflexão e o reconhecimento das determinações sociais constituintes da experiência moderna, reflexões a partir da vida danificada, como Adorno nomeou no subtítulo do Minima Moralia, em 1951. Num segundo movimento, interessam mais os processos de educação na cultura, quando Adorno menciona possíveis intervenções educacionais, desde a primeira infância, capazes de fortalecer dinâmicas psicológicas que se oponham à barbárie. Portanto, acerca da infância, vale ressaltar que Adorno considerava que a Psicanálise freudiana contribuiu com uma revolução intelectual e, a partir disso, das relações sociais, ao trazer à cena descobertas que possibilitaram maior consciência sobre a conexão entre a repressão infantil e a ignorância sobre a dinâmica psicológica da vida da criança e do adulto, modificando as relações de cuidados - afetividade - e educação entre pais e filhos (ADORNO et al., 2008).

\footnotetext{
${ }^{3}$ A pesquisa teórica intitulada $O$ entrelaçamento do amor e do pensamento na infância em Theodor W. Adorno: um estudo sobre mimese, imaginação e memória subsidiou a tese de doutorado, no programa de Pós-graduação em Educação da Universidade Federal de Santa Catarina, realizada com bolsa Capes/DS, defendida e aprovada em julho de 2017. Tal pesquisa, orientada pelo Prof. Dr. Alexandre Fernandez Vaz, compõe o programa de pesquisas Teoria Crítica, Racionalidades e Educação V (Aux. pesquisa, proj. 403624/2016-9 e 423773/2018-6; Bolsa de produtividade em pesquisa, proj. 310115/2017-5).

Educação em Revista|Belo Horizonte |v.36|e224960|2020
} 
É nesse sentido que o amor é compreendido neste texto, segundo a indicação de Adorno (1951/1992; 1971/1995) fundamentado na psicanálise freudiana, como relação libidinal, ou seja, como movimento pulsional de tentativas de ligar o desejo (Eros) ${ }^{4}$ aos objetos de satisfação de necessidades afetivas (Anankê), que são impreterivelmente constituídas nas relações culturais (FREUD, 1905/1976). Nos escritos do autor frankfurtiano o amor é algo distinto do sentimentalismo moral ou natural, mas que se apoia na esperança de um dia renunciar à dominação de si mesmo e do outro, condição para que seja possível, por meio da reflexão, opor-se à frieza difundida socialmente.

Embora, Adorno (1971/1995) considere o amor como elemento capaz de favorecer as possibilidades de resistência à frieza das relações humanas, também observa que a exigência de amor é em vão, já que as condições objetivas da realidade produzem nas pessoas disposições psicológicas contrárias ao esforço para amar e para serem amáveis. Contudo, as considerações de Adorno não partem da desesperança total no amor, mas, antes, da descrença na ingênua ideia de que o amor é de algum modo inato aos humanos, ou que seja dispensável aos indivíduos empreender esforços em suas relações afetivas e, ainda, de modo mais essencial, que possa o amor persistir ao longo do tempo sem que exista base material para sua sustentação. Pode-se ler em Constanze:

Se o amor deve representar na sociedade uma sociedade melhor, ele não é capaz de fazê-lo como um enclave pacífico, mas tão somente numa resistência consciente. Esta, contudo, exige precisamente aquele aspecto de arbítrio que lhe proíbem os burgueses, para quem o amor é jamais suficientemente natural. Amar significa ser capaz de não deixar a imediatidade atrofiarse por força da onipresente pressão da mediação, da economia, e nessa fidelidade ela se mediatiza em si mesma, torna-se uma obstinada contrapressão. Só ama quem tem força para persistir no amor. (ADORNO, 1951/1992, p. 151)

Sobretudo, nas passagens em que se propõe a pensar a Educação, Adorno menciona a relevância do amor no processo de formação cultural que tem início em fase precoce do desenvolvimento infantil. Daí a recorrência de indicações para que aqueles que se dispõem a pensar acerca das possibilidades de autonomia na Educação voltem-se para o entendimento da infância e das relações que são estabelecidas nesta fase (ADORNO, 1971/1995).

No texto Educação após Auschinitr. Adorno não deixa dúvidas quando se lembra do entendimento da Psicanálise freudiana, em suas palavras, a "psicologia mais profunda", sobre a formação do caráter na primeira infância (ADORNO, 1971/1995, p. 121). O que interessa a Adorno nesse tema é a reflexão acerca das disposições psicológicas formadas nas relações da criança com suas instituições de mediação social, e que tornam as pessoas capazes de perseguir, assassinar e cometer toda a violência e o ódio testemunhados em Auschwitz. Entretanto, para evitar que Auschwitz se repita, não basta depositar a esperança em valores diretamente opostos à frieza dos perseguidores, como um investimento na propagação do amor, por exemplo; mas, sim, considerar as contradições objetivas e as impossibilidades para a autonomia. Para isso é necessário trazer à consciência os mecanismos com os quais as pessoas voltam-se com fúria e agressividade umas contra as outras, quando tentam escapar das pressões impostas socialmente para a adaptação e a mera sobrevivência (SALGADO, 2017). Nas palavras de Adorno:

Se existe algo que pode ajudar contra a frieza como condição da desgraça, então trata-se do conhecimento dos próprios pressupostos desta, bem como da tentativa de trabalhar previamente no plano individual contra esses pressupostos. Agrada pensar que a chance é tanto maior quanto menos se erra na infância, quanto melhor são tratadas as crianças. (ADORNO, 1971/1995, p. 135)33

Com base em tais entendimentos, considera-se que a base para o desenvolvimento do amor e do pensamento parte de experiências que se iniciam com os sentidos corporais na infância em

\footnotetext{
${ }^{4} \mathrm{Na}$ mitologia grega Anankê é a deusa da inevitabilidade da vida, por isso refere-se às necessidades e restrições que a vida impõe a Eros, o deus do amor. Freud os utiliza em sua Psicanálise como símbolos de forças que se complementam e se opõem, assim como um outro para Thanatos (deus da morte) e Eros, que é o próprio princípio de ação psíquica, dos desejos que permanecem demandando suas satisfações.
}

Educação em Revista|Belo Horizonte|v.36|e224960|2020 
sua socialização, quando a criança experimenta seus desejos, diferencia-se do objeto amado, representaos, coloca-os em jogo e, nisso, pode iniciar o processo de reconhecimento sobre si mesma e o mundo. É desse modo que a mimese, a imaginação e a memória - faculdades intelectuais e sensíveis do pensamento - podem ser compreendidas como capazes de produzir elementos que se entrelaçam ao amor. Como pode ser lido em Adorno:

\begin{abstract}
Não é a memória inseparável do amor, que pretende conservar o que passa? Não é cada impulso da fantasia engendrado pelo desejo, que, deslocando os elementos do existente, transcende-os sem traí-los? A mais simples das percepções não se forma no medo da coisa percebida ou no desejo desta última? (ADORNO, 1951/1992, p. 106-107)
\end{abstract}

Para pesquisar as três faculdades foi necessário partir do estudo dos conceitos, que apenas referem-se a elas, na medida em que não podem abarcá-las em suas totalidades. O conceito captura uma parte, aquela que a teoria é capaz de sistematizar. Mas, sobretudo, quando se trata de faculdades que encontram vazão para o seu desenvolvimento mais fortemente na infância, há de se considerar os espaços fugidios, oblíquos, de certo modo, anacrônicos, aos quais a teoria deve se voltar se deseja alcançar os desvios de algo que escapa à fixação dos conceitos. Segundo Adorno (1951/1992), um movimento capaz de perceber os resíduos da história que a sociedade dominante não esgotou e que, por isso, escapam à captura do impulso dominador o conceito, podendo, então, transcender o existente.

Por esse caminho, entende-se que os estudos da infância - via faculdades da mimese, da imaginação e da memória - povoam o campo do fugaz, das ambiguidades que são suscitadas ora para justificar a realidade, ora para resistir a ela. Tais faculdades favorecem a tensão entre o pensamento esclarecido e os aspectos constituintes da razão outra que opera na infância e, ambos, ocupam centralidade ao resguardarem possibilidades para que o pensamento encontre gratificações com a realidade e com a fantasia. Desse modo, oferecem aberturas para um pensamento que busca reconhecer que aquilo que pode transcender na "sociedade dominante não é só a potencialidade desenvolvida por ela, mas também aquilo que não se enquadrou nas leis do movimento da história" (ADORNO, 1951/1992, p. 133).

\title{
MIMESE - A PRIMEIRA FACULDADE DO AMOR
}

Segundo a perspectiva de uma Teoria Crítica da Sociedade, a faculdade mimética, em seu momento inicial da formação do indivíduo, atua como mecanismo orgânico arcaico de adaptação do ser vivo ao ambiente. Diante do desconhecido, o indivíduo utiliza a capacidade de diluir-se na imagem do que imagina ser o estranho. Pode-se dizer de um movimento corporal "tateante" que num primeiro encontro se aproxima da representação do outro desconhecido, fundindo-se nesta imagem de forma prazerosa ao possibilitar a experiência com o objeto por meio do órgão sensível - o corpo - e, ao mesmo tempo, ameaçadora por não ter o domínio do objeto desconhecido (FRANCISCATTI, 2005). O corpo humano - que é natureza transformada pela história - é uma das expressões da capacidade mimética, por resguardar a memória de uma natureza mais arcaica e, em parte, incontrolável nas formas de sentir e perceber (BASSANI e VAZ, 2011; CROCHÍK, 1999); ou, se quisermos, uma rememoração pré-racional do germe da identificação - do amor.

O momento da mimese pré-racional da natureza humana, do qual toda infância ainda dá sinais com o doloroso processo de socialização, pode ser denominado original e não conceitual de aprendizagem do mundo (BASSANI e VAZ, 2011). Essa mimese original que atua no sentido contrário ao da razão esclarecida, considerada por Adorno (1951/1992, p. 136) como a "forma primitiva do amor" e princípio do pensamento mítico sobre o idêntico e o não idêntico (ADORNO; HORKHEIMER, 1947/1985), foi recalcada no estabelecimento da razão esclarecida, e por isso torna o sofrimento desse momento primitivo reificado na consciência, mas não extinto, tampouco passível de reconciliar indivíduo e natureza, sujeito e objeto. Pelo menos, enquanto as condições materiais não 
ampararem a reflexão acerca do sofrimento recalcado, tal reconciliação é, segundo Adorno (1995), projeção romântica da nostalgia (BASSANI e VAZ, 2011).

A razão esclarecida se baseia no estabelecimento de métodos que decodificam o objeto estranho por meio de conceitos formulados segundo as exigências de autopreservação. A mimese original, da qual a infância expressa resquícios, ao contrário, conta com a sensibilidade do corpo, para se aproximar do desconhecido de forma mais ou menos apaziguada, uma vez que os fins não são de dominação da natureza, mas de reconhecimento da diferença, de proximidade na distância (BASSANI e VAZ, 2011; CROCHÍK, 1999; VAZ, 2007).

Conforme Adorno e Horkheimer (1947/1985) trataram na Dialética do Esclarecimento, a passagem dessa mimese original, apaziguada com a natureza desconhecida do mundo e utilizada pelos povos primitivos como meio do conhecimento mitológico, da magia para o domínio da natureza por meio da razão, que representa o inquestionável impulso progressivo no processo de formação do sujeito e da humanidade, resguarda um momento de muito sofrimento, do qual provém o psiquismo humano tal como é conhecido, marcado pelo conflito, a contradição, o desejo e o amor-ódio de si próprio, do outro e do mundo.

A percepção do medo exacerbado de não sobreviver às ameaças sociais impele à mimese, não mais da imagem do estranho, mas do próprio estranhamento recalcado sob o mito da onisciência da razão. Nesse caminho de ilusão, de que o conceito e mais ainda o método a tudo conhecem e asseguram a resolução, a razão esclarecida recai no mito ao se desvincular da sensibilidade e, assim, afasta-se das possibilidades de estabelecer um conhecimento conciliador com a fragilidade e com o que é estranho (das Unheimlich), instaurando a astúcia como norma mimética (CROCHÍK, 1999). Cabe ao eu amedrontado imitar sua própria aniquilação para sobreviver, fazer-se de corpo morto realizando a forma perversa da mimese: a mimese da mimese (ADORNO e HORKHEIMER, 1947/1985).

Nesse sentido, se no início do processo civilizador a mimese era utilizada como meio de defesa diante dos perigos da natureza, com o desenvolvimento da razão esclarecida ela foi negada e proscrita, tornando-se alvo de uma educação enrijecida, em que o preconceito ultrapassa os limites exigidos na adaptação e opera como projeção automatizada sobre a realidade externa. A esse respeito, Maia, Silva e Bueno (2017) lembram o exemplo que Horkheimer oferece dos momentos iniciais de socialização:

Quando uma criança deixa a casa dos pais e passa a se relacionar com pessoas inicialmente estranhas, que são seus colegas de grupo na escola, ela necessita combater sua própria debilidade e impotência para que possa amadurecer suas qualidades intelectuais e emocionais. Sob contextos familiares e sociais que desfavoreçam a experiência autônoma com o mundo, essa criança se vê tentada a cristalizar a projeção como mecanismo automatizado na relação com o mundo externo. Em vez de entregar-se a um processo doloroso de elaboração da debilidade interna, a criança, juntamente com outros colegas de grupo que passam pelo mesmo processo, poderá se proteger da dor e do incômodo inevitáveis pela projeção de sua impotência em determinadas vítimas que se tornam objetos de expiação da fraqueza alheia. (MAIA, SILVA e BUENO, 2017, p. 52)

Talvez não seja excessivo ressaltar que a projeção é um dos mecanismos de defesa psíquica em que o sujeito expulsa de si e localiza no outro o conteúdo de seus próprios sentimentos, desejos e comportamentos que podem o colocar sob ameaça (FREUD, 1905/1976; LAPLANCHE e PONTALIS, 1991). Numa organização social que sustenta sua ideologia, entre outros aspectos, na dominação da natureza, a fragilidade que é própria da vida humana é tomada como fraqueza a ser combatida ${ }^{5}$.

\footnotetext{
${ }^{5}$ Segundo nos ensina a Psicanálise de Freud (1921/2011), a identificação e a representação (mimese) são parceiras num mecanismo que movimenta a afetividade de duas formas, a saber: representando o objeto amado (querer ser como ele); identificando-se com o sintoma do objeto (querer tomar seu lugar, nem que seja mimetizando seu sofrimento). Esta última forma de identificação, ao que parece, é a predominante numa sociedade massificada, em que as condições objetivas de vida obstruem a capacidade de reflexão sobre a realidade, impondo desde a infância ameaças de exclusão social caso alguma fragilidade se manifeste.
} 
As marcas da proibição mimética, que são expressões da natureza humana, são conhecidas de toda criança que tentou imitar alguém, bem como do constrangido adulto do qual escapa algo de sua natureza como o suor, o rubor, "tudo o que lembra o orgânico, a sujeira, os odores e qualquer tipo de 'mistura'[sic]" (VAZ, 2004, p. 30 - grifos no original). Marcas do próprio progresso e, de acordo com Adorno e Horkheimer (1947/1985):

O rigor com que os dominadores impediram no curso dos séculos a seus próprios descendentes, bem como às massas dominadas, a recaída em modos de vida miméticos começando pela proibição de imagens na religião, passando pela proscrição social dos atores e dos ciganos e chegando, enfim, a uma pedagogia que desacostuma as crianças de serem infantis - é a própria condição da civilização. A educação social e individual reforça nos homens seu comportamento objetivamente enquanto trabalhadores e impede-os de se perderem nas flutuações da natureza ambiente. Toda diversão, todo abandono tem algo de mimetismo. Foi se enrijecendo contra isso que o ego se forjou. (ADORNO e HORKHEIMER, $1947 / 1985$, p. 149)

Para Adorno e Horkheimer a proscrição da mimese incontrolável, aquela capaz de revelar a reação do humano por meio de sua própria natureza, foi substituída "pela manipulação organizada da mimese e, por fim, na fase histórica, pela práxis racional, isto é, pelo trabalho" (1947/1985, p. 149).

A analogia desse momento de cálculo da reação frente ao outro ameaçador por meio da razão esclarecida pode ser lida, por exemplo, na conhecida passagem de Dialética do Esclarecimento em que a personagem Ulisses usa da astúcia para salvar-se da morte pelo ciclope Polifemo denominandose "Ninguém", desse modo, abrindo mão de sua própria identidade, ao ser requisitado pelo ciclope ninguém seria levado à morte. Vale a pena a bela análise dos frankfurtianos:

O cálculo que Ulisses faz de que Polifemo, indagado por sua tribo quanto ao nome do culpado, responderia dizendo: "Ninguém" [sic] e assim ajudaria a ocultar o acontecido e a subtrair o culpado à perseguição, dá impressão de ser uma transparente racionalização. $\mathrm{Na}$ verdade, o sujeito Ulisses renega a própria identidade que o transforma em sujeito e preserva a vida por uma imitação mimética do amorfo. Ele se denomina Ninguém porque Polifemo não é um eu e a confusão do nome e da coisa impede ao bárbaro logrado escapar à armadilha: seu grito, na medida em que é um grito por vingança, permanece magicamente ligado ao nome de quem quer se vingar, e esse nome condena o grito à impotência. (ADORNO e HORKHEIMER, $1947 / 1985$, p. 63 - grifo nosso)

Em tal passagem, o conceito de mimese aparece como fio condutor de rememoração da denegação da natureza no processo de esclarecimento da razão, e é desse modo que tal conceito permeia, em grande parte, o pensamento de Adorno, podendo ser localizado didaticamente em três momentos distintos; segundo Bassani e Vaz (2011, p. 152), "na forma de um conhecimento não conceitual e expressivo, passando pelo caráter de instrumento de dominação política e encontrando seu desiderato na dialética entre espontaneidade e dominação do corpo e suas virtualidades".

Tais momentos, que marcam o reconhecimento de Adorno acerca do potencial racionalsensível da mimese, indicam que a razão mantém uma relação de amor-ódio com o fato de ter assumido para si, como procedimento instrumentalizado, a dominação de momentos que poderiam ser reconciliadores com a diferença, libertando a si mesma da ilusão de a tudo conhecer para tudo mensurar.

No pensamento esclarecido, como pode-se compreender à luz de Adorno e Horkheimer (1947/1985), a mimese encontra sua via perversa, associando-se à falsa projeção e, com isso, conformando o preconceito proveniente do enrijecimento do pensamento na relação entre sujeito e objeto, corpo e espírito, amor e ódio. Não é demais a ressalva de que o comportamento mimético é a reação do indivíduo que com medo procura diminuir a distância daquele que supõe ser um agressor (CROCHÍK, 1999). Se em seu movimento original, numa fase pré-histórica, a mimese possibilita a abertura ao reconhecimento do estranho (das Unbehagen), ao ser recalcada ela promove o ataque àquele que poderia ser identificado como o mais familiar. 
Sobre a falsa projeção e sua relação com a mimese Adorno e Horkheimer escreveram no $V I$ elemento do antissemitismo:

O antissemitismo baseia-se numa falsa projeção. Ele é o reverso da mimese genuína,
profundamente aparentada à mimese que foi recalcada, talvez o traço caracterial patológico em
que se sedimenta. Só a mimese se torna semelhante ao mundo ambiente, a falsa projeção torna
o mundo ambiente semelhante a ela. Se o exterior se torna para a primeira o modelo ao qual o
interior se ajusta, o estranho tornando-se familiar, a segunda transpõe o interior prestes a saltar
para o exterior e caracteriza o mais familiar como algo de hostil. (ADORNO e
HORKHEIMER, $1947 / 1985$, p. 154)

Desse modo, o caráter de instrumento de dominação política da mimese recalcada é inseparável das consequências de sua proscrição e restrição à magia, à arte e aos comportamentos considerados não racionais das crianças, e também das mulheres, cujos estereótipos e preconceitos aprisionam o feminino no círculo mágico da irracionalidade, e que apenas recentemente, na contramão da cultura, e não sem muito esforço, começam a serem combatidos.

No plano do pensamento racional, portanto, reivindicar a participação da faculdade mimética é investir na possibilidade que somente por meio da razão pode ser facultada, a saber, que o humano se reconcilie com sua natureza por meio do pensamento crítico, estabelecendo condições não violentas para que, enfim, o estranho (das Unheimlich) seja compartilhado sem medo e sem dominação. Trata-se de reconhecer a necessidade de por meio da crítica liberar o caminho na racionalidade para a mimese recalcada em favor da experiência, da possibilidade de fruição com o outro sem, contudo, perder-se de si mesmo. Não é esse fruir e reconhecer, se perder e se encontrar, o movimento do amor e do pensamento?

Há de se ressaltar que um pensamento crítico deve ser dialético e não mimético. Significa dizer que o pensar sensível, que a faculdade mimética em seus entrelaçamentos com as outras faculdades do pensamento, em especial a da imaginação e a da memória, não se esmorece frente aos limites e potencialidades presentes nas relações com os objetos; ao contrário, torna a representação dos objetos o impulso prazeroso e arrebatador para o aprendizado, conforme o entendimento aristotélico acerca da capacidade mimética, segundo o qual Adorno retomou ao tratar do processo de adaptação na formação do indivíduo (ADORNO e HORKHEIMER 1947/1985) e, mais tarde, em sua Teoria Estética (GAGNEBIN, 1993).

Aristóteles (2006) atribuiu à mimese a forma de operação anímica capaz de mover o afeto entre as pessoas e promover a identificação por sua capacidade de transformar o dessemelhante em semelhante, em outras palavras, impulsionar o aprendizado, mas também a possibilidade de sofrer o outro, ser afetado pelo reconhecimento de que o outro é diferente - em sua particularidade - e semelhante - na composição do universal - e, a partir disso, identificar-se nas diferenças e fragilidades compartilhadas.

Analisando as diferenças conceituais da mimese para Platão - que inaugura a necessidade de sua proscrição e controle por meio da razão ao perguntar e indicar o que deve ser imitado - e para Aristóteles - que se preocupa com a faculdade humana de mimetizar e pergunta como ocorre o impulso para a representação dos objetos -, Gagnebin (1993), com base na obra A Poética, de Aristóteles, destaca o seguinte:

A mímesis faz parte da natureza humana, caracteriza em particular o aprendizado humano. Esta ligação entre mimeisthai [capacidade mimética] e manthánein [aprendizado] insiste no componente ativo e criativo da mímesis (contra a posição platônica)[sic] e a inscreve na atividade humana por excelência, no conhecer. O aprendizado mimético, diz Aristóteles, produz prazer, agrada [...]. Este momento de prazer não é interpretado como um desvio perigoso da essência, como em Platão, mas pelo contrário, como um fator favorável, que estimula e encoraja o processo de conhecimento (importância do lúdico)[sic]. (GAGNEBIN, 1993 , p. 70-71 -grifos no original)

Para Gagnebin (1993), a forma do aprendizado mimético é específica, sobretudo, das crianças, isso ocorre pela possibilidade do pensamento tanto não se restringir ao critério de causa e 
efeito como por meio da representação mimética "engendrar semelhanças", como Benjamin (1933/1994, p. 108) retomou da filosofia de Aristóteles. O prazer que tal aprendizado proporciona advém do processo de reconhecimento dos objetos por meio da capacidade de encontrar semelhanças na diferença. Pode-se dizer, junto com Gagnebin (1993), de um princípio positivo da imaginação lúdica e artística originada pela faculdade mimética, conforme Benjamin defendeu.

Em Dialética do Esclarecimento (ADORNO e HORKHEIMER, 1947/1985), Adorno chamou a atenção de que tal faculdade há muito fora ameaçada e sucumbida por uma mimese segunda, pervertida, bem como reconhecia tal momento positivo na resistência à irracionalidade que a rememoração da natureza permite, em especial, por meio do conhecimento estético - na arte -, e do caráter lúdico do jogo que na infância aproxima as crianças de sua face natureza identificada nos animais. Conforme exemplifica a citação extraída de Teoria Estética:

Os macacos antropomorfos do jardim zoológico executam em comum o que se assemelha a actos de um clown. A conivência das crianças com os clowns é uma conivência, que os adultos lhes recusam, com a arte, não menos do que com os animais. $O$ género humano não conseguiu um tão pleno recalcamento da sua semelhança com os animais que não a possa reconhecer subitamente e ser então inundado de felicidade; a linguagem das criancinhas e dos animais parece identificar-se. (ADORNO, 1970/1988, p. 140 - grifos no original)

Freitas (2008) lembra que para Adorno a mimese é anterior à própria linguagem comunicativa, ou seja, compõe o centro da natureza humana, por isso é capaz de, por meio da arte em seu estágio imaginativo mais avançado, recuperar certa relação simbiótica entre Eros e Logos e, predominantemente, na infância, por meio da aproximação da natureza mais arcaica sem, contudo, abrir mão do princípio racional que a distingue e a aproxima do mito.

\section{IMAGINAÇÃO - A FACULDADE DA RESISTÊNCIA}

Em diálogo com Becker no texto Educaşão para quê, Adorno (1971/1995) afirma que uma educação orientada para a emancipação não se distingue de uma educação para a experiência, que por sua vez é idêntica à educação para a imaginação. Nesse caminho, ele considera que a imaginação - ou fantasia ${ }^{6}$ - cria possibilidades para que o indivíduo se coloque como "núcleo impulsionador da resistência" à mera adaptação (ADORNO, 1971/1995, p. 154).

O entendimento de que a imaginação tem como potencialidade ser resistência às exigências de adaptação pode ser encontrado não só em Adorno, mas também, de forma explícita, em obras de Marcuse (1955/1981) e Benjamin (1969/2002), e compõe um marco temporal de diálogos com a Psicanálise de Freud que serão aqui brevemente contemplados.

Em momentos distintos em que Adorno (1951/1992) qualifica a atividade imaginativa, ele diz, por exemplo, que o pensamento é filho do desejo e que a faculdade do pensamento não diz respeito somente ao desenvolvimento lógico, mas também à capacidade de realizar experiências intelectuais (ADORNO, 1971/1995), com isso, ele concorda com o conceito de imaginação/fantasia desenvolvido por Freud (1911/1976a) que pode ser compreendido como a capacidade do pensamento para mobilizar representações, criando um universo especulativo que rememore os desejos e sofrimentos recalcados ${ }^{7}$ ao serem negligenciados pela realidade.

\footnotetext{
${ }^{6}$ Nas obras pesquisadas dos autores da Teoria Crítica da Sociedade, bem como nas de Freud, o termo imaginação ou fantasia não apresentam distinções, ambos se referem à faculdade do pensamento de criar representações fictícias a partir da realidade vivida.

${ }^{7} \mathrm{O}$ recalcamento ocorre em decorrência de uma interdição cultural original aos desejos sexuais/prazer que gera uma tensão energética / nervosa na esfera do inconsciente, ou seja, produz novas exigências derivadas das exigências recalcadas e, por isso, não acessíveis à consciência, que por não serem totalmente satisfeitas tentarão romper este mecanismo de defesa por meio de representações aceitáveis, pelo menos em parte, pela consciência. Freud (1915/1976b) identificou tal mecanismo de recalque e, bem como, outras formas de defesa psíquica são estratégias de negociação entre o eu - a instância psíquica da consciência - o isso - a instância responsável pela exigência de satisfação imediata das necessidades - e o supereu - instância da internalização das leis e exigências exteriores (NASIO, 1999).

Educação em Revista|Belo Horizonte|v.36|e224960|2020
} 
Para Freud (1911/1976a) a imaginação/fantasia é fruto da cisão psíquica provocada pela substituição do princípio do prazer pelo de realidade, em que a faculdade da imaginação, ordenadora de parte do psiquismo, é regida pelo prazer (MARCUSE, 1955/1981).

É o recalque - mecanismo de defesa executor da cisão psíquica - que possibilita que tais desejos continuem resistindo na instância mental. Desse modo, a imaginação é originada de um mecanismo de defesa. Em sua atividade de criação de imagens que compõem um roteiro fictício a partir de fragmentos da realidade, possibilita momentos de fuga frente aos interditos reais. Tal fuga da realidade pode manter os desejos na consciência ou encobri-los por outros mecanismos de defesa. No primeiro caso, os desejos impulsionam as atividades criativas na produção intelectual, na arte, na brincadeira infantil ou mesmo no devaneio consciente (sonhar acordado), não danificando, por isso, a percepção da realidade. Quando envolta em outros mecanismos de defesa - poderia ser dito, os de um eu muito enfraquecido e, nisso, enrijecido pelo medo - as fantasias podem interferir nos esquemas de percepção da realidade, substituindo o existente pelas elucubrações criadas inconscientemente pelos mecanismos de defesa. A manifestação deste segundo movimento encontra sua via nos sonhos, na melhor das hipóteses, mas contribui, principalmente, para a projeção da paranoia, do preconceito e da perversão (ROUANET, 1985). De outro modo, pode ser dito que imaginar é defender os desejos em recusa à realidade tanto por meio da elaboração criativa, impulsionando uma fuga para cima, como na incapacidade de enfrentar cicatrizes advindas no contato com a realidade, realizando uma fuga para baixo (FRANCISCATTI, 2005).

Segundo a interpretação de Marcuse (1955/1981) da obra de Freud, uma vez que o processo mental foi cindido, estabelecendo esferas que distinguem um princípio de realidade (o consciente), guiado pela racionalidade, e um princípio de prazer (o inconsciente), "impotente, inconsequente e irrealista", a imaginação/fantasia ganhou certa liberdade em estabelecer suas próprias leis e verdades em oposição à realidade (MARCUSE, 1955/1981, p. 133).

A fantasia desempenha uma função das mais decisivas na estrutura mental total: liga as mais profundas camadas do inconsciente aos mais elevados produtos da consciência (arte), o sonho com a realidade; preserva os arquétipos do gênero, as perpétuas, mas reprimidas ideias da memória coletiva e individual, as imagens, tabus da liberdade. (MARCUSE, 1955/1981, p. 133).

Segundo tal entendimento, a imaginação/fantasia retém em sua estrutura as marcas dos conflitos gerados no aparelho psíquico de um período anterior à sua cisão - um "passado subhistórico" -, cuja memória da unidade entre o particular e o universal é sempre "renovada entre os indivíduos e entre esses e seu mundo" (MARCUSE, 1955/1981, p. 134). Tal memória é um retorno do homem ao período anterior ao principium individuationis, em que as normas repressivas de um princípio de realidade incitam a uma constante luta entre as forças antagônicas das pulsões . Desse modo, "no e contra o mundo do antagônico principium individuationis, a imaginação sustenta a reivindicação do indivíduo total, em união com o gênero e com o passado arcaico" (MARCUSE, 1955/1981, p. 134).

Ressalta-se que, também para Adorno (1970/1988), imaginar de modo algum é inventar algo que não corresponda à realidade existente. Nem mesmo a arte, produto objetivo exemplar da faculdade da imaginação, pode ser desvinculada dos elementos da realidade que possibilitaram a transfiguração artística. O trabalho da fantasia/imaginação é transformar a presença de algo que contradiz a racionalidade estabelecida por dentro da própria racionalidade, por meio de uma "disposição [do pensamento] sobre o momento mimético que suscita, destrói e salva o seu caráter nãoarbitrário. O arbitrário no não arbitrário é o elemento vital da arte [...]” (ADORNO, 1970/1988, p. 134).

Nesse sentido, entende-se que o caráter de arbitrariedade da imaginação, seu jogo de negação e rearranjo da realidade, não é, contudo, desregrado, ao contrário, depende de condições de certa consciência da realidade para opor-se ao realismo imposto pela dureza da adaptação, um momento não de projeção do medo, mas de sua repetição transfigurada.

Em especial, para Benjamin (2012) o tempo da infância coincide com o tempo da modernidade que possibilitou sua criação, ao menos, como uma subjetividade específica da vida 
humana, cujo ritmo e ordenação são regidos pelas leis da imaginação e da repetição. Essa lei da repetição marcaria a infância como o tempo do "fazer sempre de novo", tantas vezes quanto a experiência fizer desejar, não se perdendo totalmente quando a criança se torna adulto. A essência dessa brincadeira de repetir sobrevive como resíduo original no hábito: "Os hábitos são formas petrificadas, irreconhecíveis, de nossa primeira felicidade e de nosso primeiro terror" (BENJAMIN, 2012a, p. 271).

Tais formulações de Benjamin sobre a repetição acompanham os escritos de Freud (1920/1976c) sobre o movimento das pulsões, em que os impulsos sexuais buscam a repetição e o retorno de uma situação original, marcando, assim, a compulsão à repetição como a operação predominante do psiquismo moderno, uma dinâmica pulsional cuja meta se dirige para além de um princípio de prazer, mas que, segundo Freud, na infância se apresenta sem contrariar o princípio de prazer, já que nela, "a repetição, a reexperiência de algo idêntico, é claramente, em si mesma, uma fonte de prazer" (FREUD, 1920/1976c, p. 46). Destaca-se que para Freud (1920/1976c), os desejos infantis encontram sua movimentação nas pulsões sexuais e começam a sofrer o processo de interdição social cujas origens se encontram na relação entre natureza humana e cultura. Contudo, tais desejos podem ainda vislumbrar sua parcela de realização nos jogos e brincadeiras infantis, mobilizados por uma forma de funcionamento do pensamento que se liga à imaginação/ fantasia. Ao se tornar adulto, os jogos de representação e de realização dos desejos a partir de brincadeiras também são proscritos, pois o que se espera da atividade mental do adulto é que ela se oriente segundo uma racionalidade imposta pelas relações sociais, sobretudo pelos princípios civilizatórios de repressão sexual que subsidiam os de produtividade dos bens culturais (FREUD, 1908/1976d).

Nesse sentido, mais especificamente na infância, a faculdade da imaginação realiza um trabalho de repetição de desejos num processo de elaboração em forma de jogo que a brincadeira resguarda, portanto, em um repetir distinto da compulsão irrefletida. Ao repetir, a criança está imersa em seu próprio mundo, recriando temores e prazeres. Nesse processo de elaboração, que para a criança ocorre por meio de um jogo do pensamento, ela faz uso da capacidade mimética para colocar em ação a linguagem, a imagem e a memória de experiências e imagens conhecidas dispostas num ritual de sua própria socialização, que conhecemos como a esfera lúdica da vida.

Se a esfera do lúdico, cujo principal representante é o jogo, é para Adorno (1970/1988) a forma da repetição que empobrece a arte, restringindo-a a um ritual regressivo de adesão aos momentos práticos aos quais ela poderia se opor, na infância ele reconhece que por meio do jogo a criança alcança a percepção das contradições da realidade. Assim, "o jogo é a defesa delas" (ADORNO, 1951/1992, p. 200), de maneira que se pode dizer que na medida em que rearranja tais contradições opera contra o enfraquecimento de um princípio de consciência em desenvolvimento.

No que tange à educação das crianças, Adorno (1971/1995) diz que está entre as tarefas mais decisivas possibilitar a crítica à supervalorização do realismo manifesto no empobrecimento da linguagem e das formas de expressão na modernidade desde a infância. Faz bem pensar que abrir espaço para a imaginação frente à realidade, para o jogo lúdico no convívio entre as crianças, resguarda como potencialidade o estabelecimento do abrigo às fragilidades - amor - decorrentes dos processos de socialização na infância e, desse modo, possibilita a elaboração do medo da diferença e a restrição do preconceito apenas às necessidades de auto conservação.

\section{A FACULDADE DA MEMÓRIA - ESPERANÇA E RISCO NA LEMBRANÇA E NO ESQUECIMENTO}

Assim como a imaginação repete os conflitos da realidade transfigurando-os em favor de algum alívio para o psiquismo, a faculdade da memória mantém relação íntima com a repetição que, por sua vez, muitas vezes não é compreendida em sua profundidade. Ela diz respeito aos mecanismos primitivos de ordem fisiológica cuja meta também é auxiliar na obtenção de comodidade, estabilidade dos organismos. A partir da repetição de estímulos nervosos criam-se vias encadeadas no corpo que passam a memorizar o caminho para a obtenção das satisfações das necessidades básicas do organismo. 
Nas palavras de Türcke (2010, p. 37), autor cujo pensamento se fundamenta nos diálogos entre a Teoria Crítica e a Psicanálise freudiana: "repetição mantida é repetição que se tornou inteligente, ou seja, memória". Embora não se pretenda reconstruir aqui o caminho neurológico desse processo, é necessária a compreensão de que sua existência como representação de algo vivido que não se desvincula da ordem das necessidades primitivas da natureza orgânica, em que a inércia, a repetição e a memória são forças intrínsecas que trabalham para o alcance de certa comodidade em situação incômoda (TÜRCKE, 2010).

Nesse caminho, há uma intenção primária da memória - a de criar representações de satisfações de necessidades que se repetem no organismo e, portanto, entrelaçadas à imaginação -, que indica uma forma de operar do pensamento que por meio da "re-petição [buscar de novo]" (TÜRCKE, 2010, p. 39) imagina condições que sugerem segurança frente às necessidades emergentes ao organismo. Vale dizer, então, que a repetição carrega a tentativa de tornar presente registros de momentos anteriores que, ao serem reconhecidos, resultem em alguma segurança/comodidade, uma vez que já se conhece o caminho a ser percorrido. Tal entendimento de Türcke (2010) descreve a base biológica de que Freud ${ }^{8}$ se serviu para localizar o funcionamento da pulsão (e, posteriormente, da compulsão à repetição ${ }^{9}$ ) no psiquismo humano. As operações da repetição no pensamento não se desvencilham da imaginação, como pode ser exemplificado pela formação dos sonhos, na medida em que mobilizam imagens e registros da memória, bem como pela fixação de estereótipos que buscam informações e imagens conhecidas para a formação do preconceito.

A repetição não está para sempre limitada a vivenciar e fazer mais uma vez o anteriormente feito. Ela também pode realizar-se de tal modo que é buscado de novo aquilo que passou. Naturalmente não de modo imediato, pois o que passou se foi, mas certamente por meio de seu re-presentar imagético, acústico e linguístico. Re-petição [buscar de novo] por presencialização é sempre apenas algo imaginário, mas somente por essa imaginação sabemos o que passou, apenas desse modo há passado, história presente. (TÜRCKE, 2010, p. 39)

Nesse processo de formação do pensamento, no qual a mimese e a imaginação mobilizam lembranças sensórias residuais e factuais (representantes da dinâmica pulsional) de aprendizagens e afetividades que o indivíduo experienciou, reside, segundo Türcke (2010, p. 73), "nada menos do que o segredo da formação do pensamento, da formação da cultura, da hominização".

Türcke (2010) se fundamenta nas formulações dos autores da Teoria Crítica da Sociedade, segundo as quais a faculdade da memória aparece iluminando a capacidade de reencontro com a dor sofrida no processo de dominação empreendido na formação do indivíduo e em seus desdobramentos no curso da história. Em especial, a memória configura a possibilidade de contraposição à reificação do pensamento que culminou, por exemplo, no ódio e na frieza em relação aos judeus no contexto do nacional-socialismo, de forma que, até hoje, é necessário suscitar esforços para que as causas e as consequências do holocausto não sejam esquecidas.

Quando disseram que "toda reificação é um esquecimento", Adorno e Horkheimer (1947/1985, p. 190) se referiram ao preço que a humanidade pagou pelo desenvolvimento do conhecimento técnico. Endurecer o corpo e o pensamento à disposição dos meios técnicos exigiu

\footnotetext{
${ }^{8}$ Sobretudo a partir dos estudos da metapsicologia de Freud, o que foi desenvolvido por ele como "biologismo", segundo Marcuse (1955/1981, p. 29), "é teoria social numa dimensão profunda [...]", e suas interpretações sociológicas do homem evidenciaram tabus sociais que revelam "a base explosiva da civilização". Trata-se de uma insistente dedicação de Freud em desmistificar um entrelaçamento radical entre "civilização e barbarismo, progresso e sofrimento, liberdade e infelicidade", ambiguidades que por meio da escravidão e da coação se configuraram como preço a ser pago na dinâmica pulsional (MARCUSE, 1955/1981, p. 38).

${ }^{9}$ A compulsão à repetição pode ser compreendida como dinâmica psíquica decorrente das operações dos mecanismos de defesa, as pulsões são reprimidas em sua finalidade (ligar-se aos objetos de prazer), elas, então, tornam-se sem objeto definido, e seu movimento em busca de evitar o desprazer tende a regredir a um estado anterior, cujo repouso, ou uma excitação menor, lhes garanta certa tranquilidade e quietude (prazer). Segundo a teoria psicanalítica, o movimento de retorno e de regressão a um estado anterior, próprio de todo organismo vivo, é o que caracteriza a compulsão à repetição, que se tornará predominante no funcionamento psíquico, na medida em que as repressões do meio externo incidem compulsivamente no recalque das pulsões (FREUD, 1905/1976).
}

Educação em Revista|Belo Horizonte|v.36|e224960|2020 
afastar a lembrança da dor que a natureza impõe. Desse modo, para esquecer a dor é preciso naturalizar a cegueira para o sofrimento de si mesmo e daquele imputado ao outro. Reificar não é viver sem a dor esquecida. É um não-viver ao contentar-se com a falsa felicidade, "um estado apático e vegetativo, pobre como a vida dos animais e no melhor dos casos a ausência da consciência da infelicidade" (ADORNO e HORKHEIMER, 1947/1985, p. 59).

É nesse sentido que, em Adorno (1951/1992), rememorar a dor promete a elaboração do passado a partir da consciência do medo e da violência sofrida. Entrar em contato com as cicatrizes e, neste enfrentamento, liberar a esperança de superar o sofrimento e, quem sabe, evitar sua repetição. A faculdade da memória é a única capaz de permitir a perlaboração do que se passou e, desse modo, reivindicar a salvação da história naturalizada e petrificada sob a ideologia que faz crer que não é possível alterar o curso da cultura a favor de tempos melhores. Sobre isso Adorno escreveu:

\begin{abstract}
Assim, quando esperamos a salvação, uma voz nos diz que a esperança é vã e, no entanto, é ela apenas, a imponente esperança, que nos permite cobrar alento. Nenhuma contemplação é capaz de outra coisa senão redesenhar pacientemente em figuras e esboços sempre novos a ambiguidade da melancolia. (ADORNO, 1951/1992, p. 106)
\end{abstract}

Lembrar e salvar orientam o redesenho da memória ao evocar a representação das imagens do passado atualizadas pelo presente. Vale dizer que para Adorno (1951/1992) é o trabalho criativo da mimese e da imaginação que rearranja e organiza as imagens de acordo com a disposição psíquica e as percepções atuais da consciência, decodificando as lembranças individuais a partir do sistema de representações socialmente mediadas.

Entende-se que o trabalho de rememoração que a faculdade da memória realiza une o pensamento e a afetividade - que só podem surgir com a identificação com o diferente - na promessa de reconciliação que só o perdão (que não é esquecimento) possibilita àquele que se reencontrou com a violência sofrida ser capaz de seguir, entretanto, consciente da própria história. Trata-se de um movimento inverso ao do proclamado pela racionalidade que tenta abolir a mimese e a imaginação para se afirmar como realista e, com isso, atrofia a memória. Contudo, apesar de ser indispensável a oferta segura de condições objetivas na esfera social, para que lembrar não seja um risco à autoconservação tornou-se imprescindível o esclarecimento subjetivo, capaz de fortalecer o eu para suportar as lembranças. Nas palavras de Adorno (1971/1995, p. 48): “A elaboração do passado como esclarecimento é essencialmente uma tal inflexão em direção ao sujeito, reforçando a sua autoconsciência e, por esta via, também o seu eu".

Ocupar-se do passado desvia a energia necessária para as metas estipuladas na vida prática presente e, é desse modo, que não abrir mão da memória é sofrer as ameaças por não cumprir as exigências da administração da vida. "Quem não se ocupa com pensamentos inúteis não joga areia na engrenagem" (ADORNO, 1971/1995, p. 34). Significa dizer que a lembrança constante também pode paralisar e, por si só, não reanima a esperança. Melhor seria lembrar, elaborar e poder esquecer, discernindo sobre a experiência vivida e evitando a repetição dos sofrimentos.

Enquanto os indivíduos não encontrarem condições de segurança na cultura, repetir o sofrimento é a saída para diminuir a dor outrora sentida, até que ela seja familiar o bastante para não causar espanto. Esse é o caminho da frieza diante do próprio sofrimento e, nisso, da reprodução compulsiva da violência e da frieza nas relações com os outros. Desse modo, a compulsão à repetição é o modo de operar da memória dos indivíduos ameaçados por um passado que permanece em aberto à espera de perdão daquilo que se pode perdoar e de justiça ao que não tem perdão.

\title{
MEMÓRIA E INFÂNCIA: O RELAMPEJAR DE PORTAIS DE SEGURANÇA
}

Vaz (2006) escreve que, ao analisar as expressões da modernidade, Walter Benjamin toma a cidade grande como sua referência para tratar do espaço mais do que do tempo moderno. Essa percepção acerca do espaço da modernidade é o que subsidiará a ideia de memória e história em Benjamin. Uma memória que se desenrola apoiada mais no território do que na linearidade do tempo. Em oposição a uma organização dos fatos da história num tempo cronológico e progressivo, o que 
Benjamin oferece, em termos políticos e epistemológicos, é uma historiografia que se movimenta entre as nuances da memória espacial e temporal. Nas palavras de Vaz:

\begin{abstract}
Só assim, correspondendo a uma espacialização da memória, é possível pensar a história como um palco de ruínas, como sugere a ensaísta Susan Sontag (1986), como um amontoado de escombros calcinados e acumulados como restos sobre as quais o progresso e seus discursos legitimadores - à direita e à esquerda - nos querem fazer esquecer. (VAZ, 2006, p. 36)
\end{abstract}

Não é em vão que Benjamin (2012, p. 91) em seu aforismo Esconderijos diz que o momento de se esconder na brincadeira da infância plasma o medo e a libertação; e, por essa experiência de se fundir no tempo e no espaço, a casa da infância - "arsenal de máscaras" (BENJAMIN, 2012, p. 92) - guardará abrigos seguros nos quais o adulto poderá ter a felicidade de retornar por meio de suas reminiscências e encontrar seus portais de segurança, pois em cada porta da casa há um momento de enfrentamento e ruptura, o momento em que a criança volta para a casa mágica escavando os segredos. No encontro com portais de segurança que a criança encontrou reside a possibilidade de reflexão sobre o passado em aberto e, nisso, o pensamento acerca da sua própria história que não se separa da universal (BENJAMIN, 2012).

Com essa filosofia política e, podemos dizer, sensível sobre os contornos espaciais da história, Benjamin abre um caminho intelectual para o entendimento dos escombros recalcados na cronologia oficial das sociedades. No que diz respeito à infância, ele iluminou nas escavações da memória as pistas desprezadas nos espaços e tempos escolares, nos livros infantis, nos brinquedos, nas coleções, nas ruas, compondo um cenário em que cada elemento relampeja o passado e segundo os quais o pensamento encontra passagens para a análise de seus momentos de atividade e passividade tempos da experiência -, desse modo, pode contextualizar a história das produções sociais.

Trata-se de não submeter o conhecimento a uma razão que restringe a realidade às suas mensurações, portanto, contando com a reivindicação de que a racionalidade deve lembrar-se de seus componentes materiais: intelectuais e sensíveis. Nesse sentido, em Benjamin e em Adorno, mas também Horkheimer, podemos encontrar a preocupação com uma educação dos sentidos, ou melhor, a reflexão sobre uma relação dialética com o mundo que dispõe ao pensamento uma memória sensorial, constituída no contato com os objetos e os espaços da realidade.

Em seus escritos sobre a infância, Benjamin exercita uma memória que não desistiu da experiência, que detém detalhes impressos nos sentidos e por isso pode narrar espaços compartilhados não apenas por determinadas crianças e pessoas da cidade, mas pela materialidade ocupada pela infância de seu tempo. A história-memória que deixa suas marcas no corpo e no espírito parece ser aquilo que dificulta o esquecimento ao tramar a produção das lembranças nos espaços acessíveis ao corpo, ela é "ancorada no corpo, é composta por um momento somático" (VAZ, 2006, p. 43).

Se, para Benjamin, falar da infância é ocupar o ponto de vista de quem se lembra de suas possíveis operações intelectuais e sensíveis, a partir de toda uma materialidade e seus jogos com o corpo, para Adorno, enfrentar esta memória é alcançar os espaços da história em que o particular e o universal contam juntos os horrores e as esperanças da materialidade do mundo. Ambos os autores lembram que os indícios de quem somos e do que está por vir são mais familiares do que estranhos no curso do progresso. Como nestas lembranças de Adorno em Minima Moralia, em que a memória se aproveita da linguagem para a rememoração de uma melancolia conhecida:

Numa noite de tristeza inconsolável, eu me surpreendi fazendo uso do subjuntivo
ridiculamente errado de um verbo que, ele próprio, já não pertencia de todo ao alemão padrão,
mas faz parte do dialeto de minha cidade natal. Desde os primeiros anos escolares não havia
mais ouvido essa forma errada tão familiar, menos ainda empregado. Uma melancolia, que me
arrastava de maneira irresistível para o abismo da infância, despertou esse antigo som, que
aguardava impotente lá no fundo. Como um eco, a linguagem devolveu-me a humilhação que
a infelicidade me infligiu esquecendo o que eu sou. (ADORNO, 1951/1992, p. 96)

A palavra, o som e a linguagem constituem parte da estrutura perceptiva da memória cuja maior expressão é a narração. Narrar não é transmitir informações e acontecimentos, mas compartilhar 
experiências. Não é demais repetir que nessa comunicação compartilhada a mimese e a imaginação são parceiras na reorganização da memória, e sua potência é tal que suscita a cura dos sofrimentos esquecidos. Seguindo os ensinamentos de Benjamin, Vaz aponta que:

Se a experiência é aquela tessitura objetiva e subjetiva, que se vitaliza apenas quando pode ser narrada, compartilhada, trazida ao plano da consciência, é porque, de fato, narrar e curar se cruzam no encontro entre corpo e pensamento, entre os sentidos humanos, capazes de interagir, e os significados, os conceitos, que elucidam e rompem com o passado mítico que aprisiona, que adoece. (VAZ, 2010, p. 43)

Conforme Benjamin (1989) ensinou, o fato de a narração ter sido substituída, primeiro pelo excesso de informações na modernidade e depois pela sensação (em seu caráter moderno de percepção do incomum e do espetacular), contribuiu para a atrofia da experiência, que é o material fundamental da memória. Talvez por isso, ao narrar suas memórias da infância, Benjamin se dedicou a imprimir em cada narrativa, de formas distintas, porém ricas em imagens, as experiências que o corpo guardou das histórias contadas, dos sons, das mãos desbravadoras de livros, objetos, sabores.

A experiência vivida na infância, contudo, não está deliberadamente acessível à consciência e sua evocação é incompatível com a lembrança institucionalizada, com o pensamento que administra a prescrição social dos eventos que julga ser importante lembrar, geralmente, para obter algum tipo de vantagem ou prestígio nas relações de troca. Pelo contrário, diz Adorno:

O momento fugidio consegue viver no esquecimento murmurante, sobre o qual vem incidir o raio que o faz relampejar: querer possuí-lo já é tê-lo perdido. O rico buquê que a criança carrega para casa por ordem da mãe poderia ficar preso atrás do espelho, como os buquês artificiais de sessenta anos atrás; ao final, disso resultará algo como o instantâneo de uma viagem, tirado com sofreguidão e onde se espalham como detritos na paisagem aqueles que dela nada viram e arrebatam como recordação no nada. (ADORNO, 1951/1992, p. 98)

Cada fase do desenvolvimento infantil promete, ao menos, momentos fugidios de rupturas com as exigências de produtividade e com o tempo ocupado e acelerado pelo ritmo tecnológico. Contudo, quando o consumo de imagens, veiculadas por dispositivos de última tecnologia (bigh-tech), passa a ocupar cada vez mais o tempo da infância, mediando as brincadeiras e as relações de amizades (e de inimizades), distraindo-as constantemente, cabe perguntar se em alguns anos haverá um registro mnêmico capaz de relampejar abrigos seguros no presente. Ao que interessa à certa disposição para o entrelaçamento do amor e do pensamento, seria importante perguntar se crianças com mentes distraídas e olhares concentrados nos aparatos tecnológicos encontram brechas para fundirem-se mimeticamente nas experiências, para movimentarem imagens do pensamento no rearranjo da realidade em nome dos desejos e, por fim, para reterem algo do parco contato com os sentidos no trabalho de perlaboração da memória.

\section{NOTAS FINAIS}

Com base nos resultados da pesquisa realizada, as faculdades da mimese, da imaginação e da memória suscitam um amparo na infância. Suas formas de operar no pensamento entram em ação por meio de mecanismos psíquicos de defesa da consciência, não em repúdio ao outro, mas para se comunicar com ele e com o mundo; isso ocorre ao entrelaçar os processos orgânicos mais primitivos da natureza humana ao desenvolvimento dos processos superiores que a cultura possibilita, como a linguagem e a narração, por exemplo.

É desse modo que a mimese, a imaginação e a memória em Adorno são, de certo modo, inseparáveis. Uma remete à outra por meio da capacidade do pensamento de criar representações, ou seja, mobilizar uma imitação sensível das imagens e, nisso, rememorar os escombros da história psíquica recalcada. Juntas, estas faculdades na infância oferecem a força e a direção para que o pensamento, ainda não sucumbido totalmente às exigências da razão, busque apoio na dinâmica pulsional, nos desejos de fundir-se na vida fazendo uso de sua face natureza para brincar diante da e com a realidade. Poder rearranjar o mundo na brincadeira, rir e chorar sem ter que prestar contas a um 
super-eu tirano, que não tarda será desenvolvido em resposta à autoconservação, parece ser o jogo mais feliz da infância.

Jogar com a fantasia, fortalecendo a ação das faculdades da mimese, da imaginação e da memória, permite acessar uma esfera psíquica que fica, em parte, de fora do controle racional que obsta o movimento do amor. Desse modo, a criança, de forma similar ao artista, pode encontrar sua parcela de resistência à renúncia pulsional. A fantasia/imaginação contém, assim, como potencialidade, uma específica independência das pressões externas e uma força na estrutura mental que junta representações miméticas da imagem e da memória suficientes para reivindicar os desejos reprimidos pelas exigências sociais (MARCUSE, 1955/1981). Nesse sentido, o entrelaçar das faculdades da mimese, da imaginação e da memória testemunha aquilo que permanece conflitante na convivência entre os indivíduos, a saber: a reunião do pensamento e do amor, de uma racionalidade capaz de abrir mão da dominação de si mesmo e do outro por identificar-se com a diferença e a fragilidade compartilhadas. Desse modo, tal entrelaçar testemunha a potencialidade humana em persistir em seus desejos e esperanças, caso tais faculdades não sejam subsumidas à força irracional da propagação do medo e do ódio na cultura.

\section{REFERÊNCIAS}

ADORNO, Theodor W. Educação e emancipação. Trad. W. L. Maar. São Paulo: Paz e Terra, 1995. 190p. (Obra original publicada em 1971).

- Minima Moralia: reflexões a partir da vida danificada. Trad. L. E. Bicca. 2ed. São Paulo: Ática. 1992. 216p. (Obra original publicada em 1951).

Teoria Estética. Trad. A. Mourão. Lisboa - Portugal: Edições 70, 1988. 408p. (Obra original publicada em 1970).

ADORNO, Theodor W. et al. Estudios sobre la personalidad autoritaria. In: Th. W. Adorno Escritos Sociológicos II Vol 1. Madrid: Ediciones Akal S. A., 2008, pp. 151-525. (Publicação original 1975. Obra Original 1950/1969). PDF Disponível em: https://pt.scribd.com/document/109644633/Adorno-Th-W-Escritos-Sociologicos-II-Vol-1. Acesso em $21 / 03 / 2017$.

ADORNO, Theodor W.; HORKHEIMER, Max. Dialética do Esclarecimento: fragmentos filosóficos. Trad. G. A. Almeida. Rio de Janeiro: Jorge Zahar, 1985. 223p. (Obra original publicada em 1947 , reimpressão em 2006).

ARISTÓTELES. De anima. Trad. M C. G. dos Reis. São Paulo: Editora 34, 2006.

BASSANI, Jaison J.; VAZ, Alexandre F. Mimesis e rememoração da natureza no sujeito em Theodor W. Adorno: para pensar a educação do corpo na escola. Pro-Posições. Campinas, 2011, v. 22, n. 1. (64) jan./abr. 2011. pp. 151-165. Disponível em: http://www.scielo.br/pdf/pp/v22n1/12.pdf. Acesso em $12 / 03 / 2015$.

BENJAMIN, Walter. Magia e técnica, arte e politica: ensaios sobre literatura e história da cultura. Trad. S. P. Rouanet. Prefácio J. M. Gagnebin. 8ed. São Paulo: Brasiliense, 2012. 271p.

Obras escolbidas II: Rua de Mão Única. Trad. R. T. Filho; J. C. M. Barbosa. Rev. téc. M.

Seligmann-Silva.6ed. São Paulo: Brasileiense, 2012a.

. Brinquedos e jogos. In - Reflexões sobre a criança, o brinquedo e a educação Walter Benjamin.

Trad. M. V. Mazzari. 2 ed. São Paulo: Editora 34, 2002. pp. 95-102. Reimpressão 2011. (Obra Original publicada em 1969). 
- A doutrina das semelhanças. In:

- Magia e técnica, arte e política: ensaios sobre literatura e

história da cultura. Trad. S. P. Rouanet. Prefácio J. M. Gagnebin. 7ed. São Paulo: Brasiliense, 1994. pp. 108-113 (Obra original publicada em 1933).

Sobre alguns temas em Baudelaire. In:

Obras escolbidas III:Charles Baudelaire um lírico no auge do capitalismo. Trad. H. A. Baptista.. São Paulo: Editora Brasiliense, 1989. pp. 103-149 (Obra original publicada em 1939).

CROCHÍK, José Leon. A corporalidade e a formação humana: uma análise a partir da teoria crítica. Discorpo. São Paulo, PUC/SP, 1999, n.9. pp. 11-21.

FRANCISCATTI, Kety Valéria Simões. A maldição da individuação: reflexões sobre o entrelaçamento prazer-medo e a expressão literária. Tese (Doutorado em Psicologia) - Pontifícia Universidade Católica de São Paulo. São Paulo, p. 231. 2005.

FREITAS, Nivaldo. Apontamento sobre mímesis em Adorno e Benjamin. 2008. Disponível em: www.ip.usp.br/laboratorios/lapa/versaoportugues/2c60a.pdf. Acesso em 21/03/2017.

FREUD, Sigmund. Três ensaios sobre a teoria da sexualidade. In: Obras psicológicas completas de Sigmund Freud: edição standard brasileira. Vol. VII. Trad. J. O. A. Abreu. Rio de Janeiro: Imago, 1976. pp. 118-229. (Obra original publicada em 1905).

Formulações sobre os dois princípios de funcionamento mental. In: Obras psicológicas completas de Sigmund Freud: edição standard brasileira. Trad. J. O. A. Abreu. Rio de Janeiro: Imago, 1976a. v. 12. pp. 273-286. (Obra original publicada em 1911).

O Recalque. In: Obras psicológicas completas de Sigmund Freud: edição standard brasileira. Trad. J. O. A. Abreu. Rio de Janeiro: Imago, 1976b. v. 1. pp. 175-193. (Obra original publicada em 1915).

Além do princípio de prazer. In: Obras psicológicas completas de Sigmund Freud: edição standard brasileira. Trad. J. O. A. Abreu. Rio de Janeiro: Imago, 1976c. v. 13. pp. 11-85. (Obra original publicada em 1920).

Escritores criativos e devaneio. In: Obras psicológicas completas de Sigmund Frend: edição standard brasileira. Trad. J. O. A. Abreu. Rio de Janeiro: Imago, 1976d. v. 9. pp. 135-143. (Obra original publicada em 1908).

. Psicologia das Massas e Análise do Eu. In: Psicologia das massas e análise do Eu e outros textos (1921-1923). Trad. P. C. de Souza. São Paulo: Companhia das Letras, 2011. 296p. (Obra original publicada em 1921).

GAGNEBIN, Jeanne-Marie. Do conceito de mímesis no pensamento de Adorno e Benjamin. Perspectivas. São Paulo. 1993, n. 16. pp. 67-86. Disponível em: http://seer.fclar.unesp.br/perspectivas/article/view/771. Acesso em 25/01/2017.

LAPLANCHE, J. \& PONTALIS. Vocabulário da Psicanálise. Trad. P. Tamem. 11ed. São Paulo: Martins Fontes, 1991.

MAIA, Ari F.; SILVA, Divino J.; BUENO, Sinésio F. 10 lições sobre Horkheimer. Petrópolis: Vozes, 2017. 116p.

MARCUSE, Herbert. Eros e civilização: uma interpretação filosófica do pensamento de Freud. 8. ed. Rio de Janeiro: Zahar Editores, 1981. 232p. (Obra original publicada em 1955).

NASIO, Juan-David. O prazer de ler Freud. Trad. L. Magalhães. Rio de Janeiro: Ed. Jorge Zahar, 1999. $109 \mathrm{p}$. 
ROUANET, Paulo Sérgio. O espaço freudiano. In: 1985. pp. 199-226. . A razão cativa. 3ed. São Paulo: Brasiliense,

SALGADO, Mara. Entrelaçamento do amor e do pensamento na infancia em Theodor W. Adorno: um estudo sobre mimese, imaginação e memória. Tese(Doutorado em Educação) - Universidade Federal de Santa Catarina. Florianópolis, p.152. 2017.

SANTOS, Patrícia da Silva. Infância e promessa: notas baseadas no pensamento de Theodor Adorno. Pro-posições. Campinas, 2018, v. 29, n. 3. pp. 323-338. Disponível em:

http://www.scielo.br/pdf/pp/v29n3/0103-7307-pp-29-3-0323.pdf. Acesso em: 19/09/2019.

TÜRCKE, Christoph. Filosofia do sonho. Trad. P. R. Schneider. Ijuí: Ed. Unijuí, 2010. 328p.

VAZ, Alexandre Fernandez. Educação, experiência, sentidos do corpo e da infância: um estudo experimental em escritos de Walter Benjamin. In: . Experiência, educação e contemporaneidade. Org. P. A. Pagni e R. P. Gelamo. Marília, SP: Poesis, 2010. pp. 35-48.

. Corporalidade e formação na obra de Theodor W. Adorno: questões para reflexão crítica e para as práticas corporais. Perspectiva. Florianópolis. 22 (Especial), 2004. pp. 21-49. Disponível em http://www.ced.ufsc.br/nucleos/nup/perspectiva.html. Acesso em 02/05/2009.

- Marcas do corpo escolarizado, inventário do acúmulo de ruínas: sobre a articulação entre memória e filosofia da história em Walter Benjamin e Theodor W. Adorno. In: Educação do corpo na escola brasileira. Org. M. A. T. de Oliveira. Campinas, SP: Autores Associados, 2006. pp. 35-56.

. Notas conceituais sobre mímeses e educação do corpo em Max Horkheimer e Theodor W. Adorno. In:___ PUCCI, Bruno; GOERGEN, Pedro; FRANCO, Renato (Orgs.). Dialética negativa, estética e Educação. Campinas: Alínea, 2007. pp. 189-202.

Submetido: $07 / 06 / 2019$

Aprovado: 21/10/2019 